\title{
Apresentação
}

\section{Subjetividades em jogo nos movimentos de migração ${ }^{1}$}

A globalização, conforme problematizada por Ianni (1996) e Giddens (1991), tem como principal desdobramento a intensificação das relações sociais em larga escala no mundo pós-moderno, devido, dentre outros fatores, ao surpreendente desenvolvimento de métodos de conexão entre comunidades próximas e distantes, favorecendo, assim, a constituição de redes mundiais. $O$ esgarçamento da noção de fronteira, a relativização do tempo e a pluralidade da conectividade, decorrentes do desenvolvimento tecnológico promovido e encorajado pelos processos globalizantes, favorecem e incentivam os movimentos de mobilidade global.

Um deles que ganhou força com a globalização foi a migração. Tradicionalmente, os movimentos migratórios são entendidos como investidas de mobilidade espacial entre países e regiões por um longo período de tempo, visando o estabelecimento de moradia. Entretanto, diante do efeito do "globalismo" (IANNI, 1996), que tornou o mundo menor, mais ágil e, aparentemente, menos fragmentado em fronteiras estanques, proponho uma ampliação danoção de migração que possibilitará articular os termos que constituem o tema deste número especial: migração, linguagem e subjetividade. O pressuposto que embasa esta proposta é de que a migração engendramovimentos de desterritorialização espacial e subjetiva pelos quais alguém tem sua ligação com o lugar por ele considerado "natal" e com sua constituição identitária desestabilizada em função da radicalidade da experiência com a alteridade proporcionada pela experiência com e na estrangeiridade. Assim, a noção de migração pode ser estendida para abarcar fluxos de pessoas entre regiões, visando uma permanência em dado território, durante certo período de tempo, mesmo quando o objetivo não é o de fixar moradia. Em grande parte impulsionadas pelo desejo de experimentar outro modus vivendi reputado como melhor, mais vantajoso ou

\footnotetext{
1 Agradeço à CAPES pelo apoio, por meio do Projeto Casadinho, que possibilitou a proposta deste número especial.
} 
simplesmente exótico, os migrantes deixam seus territórios de origem para se aventurar em terras estrangeiras.

Entretanto, é justamente a estrangeridade que convoca, para o migrante, a experiência da ambivalência vivida em sua radicalidade, acarretando desdobramentos para a subjetividade dos que migram e daqueles que os recebem. São as várias manifestações desses desdobramentos que constituem o tema deste número especial da Revista Domínios de Lingu@agem, dedicado à memória da Profa. Elzira Uyeno, ela mesma filha de (i)migrantes e constituída por uma inquietação característica daqueles que se aventuram por territórios de um saber não sabido, como itine(r)rantes, que, na errância, acabam por inventar um modo singular de (con)viver com o estranho e produzem, a partir dele, laço social (cf. LACAN, 1992[1969²]).

A fim de desmembrar a problemática em questão, nesta apresentação explorarei três aspectos da migração que podem incidir na subjetividade dos envolvidos no processo e que são contemplados direta ou indiretamente nos artigos que compõem este número. Primeiramente, a experiência de estrangeiridade e seus efeitos na subjetividade daqueles que migram e daqueles que os recebem. Como decorrência dessa primeira discussão, proponho refletir sobre a representação da terra ou país natal e a representação de terra ou país de acolhida, que sofrem a injunção de ressignificações provocadas pela estrangeiridade. Por fim, problematizo como a língua do território ou país de acolhida se configura um meio por meio do qual a experiência de estrangeiridade se configura no duplo estranho-familiar, o unheimilich freudiano, possibilitando, por um lado, um encontro com um novo universo discursivo sedutor e, por outro, o confronto com o que já se encontra estabilizado pelas e nas palavras da língua materna.

A noção de subjetividade aqui se refere à perspectiva dos estudos sobre o discurso que se deixam afetar pelo conceito de sujeito da psicanálise. Assim, a subjetividade é entendida como um construto discursivo sempre passível de ser (re)construído pela via da linguagem nas relações sujeito-mundo, a partir de elementos subjetivados.

A experiência de estrangeiridadeé resultante da radical alteridade que se vivencia num território espacial e/ou subjetivo representado como estranho. A alteridade é

\footnotetext{
${ }^{2}$ A segunda data refere-se à do copyright.
} 
fundamental na constituição subjetiva, na medida em que só consigo me ver representado como possuidor de uma certa unidade por meio do olhar e do dizer do outro, pois o outro, que nos é altero, porta o campo do Outro, suscitador de nossas identificações. Nas desestabilizações das amarras identificatórias, pode se configurar para um sujeito sua condição de estrangeiro. Nesse sentido, todos nós, migrantes ou não, estamos sujeitos à experiência da estrangeiridade.

Entretanto, tal experiência é inevitável nos deslocamentos topológicos. Acomodar o novo poupandoalgumas das ancoragens que constituem aquele que migra, enfrentar o diferente, incorporá-lo ou não, estranhar-se diante do estranho que surpreendentemente pode parecer familiar, confrontar ou descontruir estereótipos são algumas das empreitadas com as quais alguém que migra se vê envolvidò. Assim, diante da valorização no novo, do inusitado, do diferente, do exótico, que se materializa na demanda configurada para alguns sujeitos de desenraizar-se, cruzar fronteiras, viver a diversidade cultural, muitos desafiam a pretensa familiaridade que desfrutam na terra considerada "natal" e partem para o "estrangeiro". Nessa empreitada, são confrontados com limites não explicitados pela propagada globalização. Um deles é a política cada vez mais extremista em relação ao acolhimento de migrantes ou a inclusão dos considerados “minorias". Vários são os exemplos. Na Europa, políticos extremistas ganham cada vez mais popularidade e movimentos xenófobos se espalham em escala surpreendente. Recentemente no Brasil, a imprensa noticiou com estardalhaço a remoção de imigrantes haitianos do estado do Acre para o estado de São Paulo. Ou ainda, povos indígenas, obrigados no decorrer de sua história a migrar cada vez mais para o interior sob a promessa da garantia de terras e que hoje se veem no centro de políticas que dizem incluir, mas os excluem exatamente por aquilo que os torna exóticos: a diferença.

O diferente incomoda na medida em que enseja a descoberta do desconhecido que nos habita e nos constitui, escancarando a ilusão de familiaridade que sustenta a instância do eu. No encontro com o diferente, tanto o migrante como o que o acolhe se encaram na dupla via da subjetivação: se deixar subjetivar para subjetivar traços do novo e/ou resistir. Ao mesmo tempo, portanto, em que o estrangeiro nos fascina por seu exotismo e pela possibilidade de descobrir nele aquilo que falta em nós, o encontro com o estranho nos assusta. Segundo Koltai (2005, p. 177): “A simultaneidade do encontro 
com a rejeição explica que, (...) no mundo moderno, o estrangeiro seja aquele que nos fascina e cujo gozo almejamos, ou aquele que nos assusta e cujo gozo nos amedronta e nos é intolerável". Residiria aí uma das origens da xenofobia.

$\mathrm{O}$ estranho desestabiliza o eu. As possíveis novas ancoragens se darão naquilo que puder ser representado como familiar em meio ao estranhamento, presentificando tanto para aquele que migra como para o que o acolhe a experiência do estranhofamiliar, o unheimilichfreudiano. Em outras palavras, a sensação de inquietude diante do que se afigura como estranho remete justamente a algo muito íntimo constitutivodo sujeito, algo que deveria permanecer em segredo e/ou encoberto, mas que, diante da possibilidade de ser suscitado, incomoda, angustia. Entretanto, a chance de alguém instaurar novas e outras identificações reside justamente na desestabilização que o estranhamento enseja. Assim, os que migram e os que o acolhem estão diante do desafio de encarar o desconhecido com a disposição de colher do encontro-confronto com o estranho a oportunidade de reinventar outras formas de ser e de estar no mundo.

Para o migrante, a experiência na e com a estrangeiridade coloca-o, ainda, num espaço contraditório de provisoriedade subjetiva devido, dentre outros fatores, à coexistência do desejo de retorno e o de permanência (OLIVEIRA, 2005).A saudade e a nostalgia de compartilhar um universo cultural imaginado uno, coeso e totalmente familiar sustenta o desejo de retorno. Território revestido de uma aura que o torna imaculado, a terra natal é, comumente,objeto das reminiscências mais acalentadas e de inúmeras comparações que a tem como termo referenciador. As comparações podem, inclusive, constituir saídas para o desconforto, na medida em que provém meios de organização e de discursivização da experiência de estrangeiridade. Confrontado com a estrangeiridade, o migrante recalca, muitas vezes, o fato de que os motivos de seu êxodo nasceram da inquietude diante da aparente homogeneidade e estabilidade desfrutadas na terra natal e anseia, mesmo que, por vezes, timidamente, para ela retornar. Essa provisoriedade provê ao migrante uma certa referência a partir da qual possa afirmar ou (des)construir identificações, ao manter na esperança a possibilidade de voltar a usufruir o pretenso conforto daquilo que o enredou e o engendrou: sua cultura e terra natal.

Simultaneamente, a migração projeta para um território alguma medida de acolhida. Os estudos sobre migração tem denominado os territórios que recebem migrantes de países, regiões ou territórios de acolhimento ou acolhida. O termo suscita 
os sentidos de recepção, proteção, refúgio. De fato, as propagadas fronteiras esgarçadas pela globalização contribuem para uma pretensa conciliação universal que permitiria exercer uma hospitalidade calcada no pressuposto de que a tão popularizada "diversidade cultural" é bem-vinda. A diferença entre o estrangeiro e o nativo seria amenizada em nome de um universalismo cosmopolita.

O princípio por detrás de tal movimento pode ser remetido à oikeiósis estóica ${ }^{3}$. Tendo como objetivo desenvolver uma ética calcada na conciliação, oikeiósis consistia na tendência almejada de apropriar-se do si próprio e de tudo o mais que fosse capaz de conserva-lo com o objetivo de evitar a confrontação e alcançar a felicidade. Acolher o que migra dentro do celebrado cenário globalizante, portanto, poderia estar embasado nessa tendência conciliatória que motiva o intercâmbio cultural como um meio de integrar e valorizar o diferente. Ocorre que, assim como no estoicismo, espera-se que o migrante, por sua vez, integre e viva sob o código da cultura de acolhida, obedeça e defenda suas leis, assemelhe-se e celebre seu anfitrião que com ele se concilia. Ai daquele que insiste em marcar sua estrangeiridade em meio a acolhidaoferecida, portanto. A esse respeito, Kristeva (1994, p. 65) adverte:

Sem dúvida parece que o estoicismo é menos um pensamento a respeito do outro que integraria a diferença do estrangeiro do que uma autarquia que assimila o outro e o apaga sob o denominador comum da razão, caindo na categoria de insensato aquele que não se enquadrar ali.

A designação território natal e de acolhida traz consigo, então, a questão da hospitalidade.Se por um lado o caráter de acolhimento reputado à terra natal é projetado ao território que recebe o migrante, por outro, os modos como se desenrola esse processo são bastante conflituosos. Nesse sentido, a problematização que Derrida empreende em sua entrevista à Anne Dufourmantele (2003) sobre a hospitalidade nos convida a pensar na ambivalência que perpassa o que acolhe o migrante. Partindo da exploração dos sentidos do radical da palavra "hóspede" em francês, o autor explora a aporia entre o direito moral e o dever de humanidade de acolher o outro sem reservas, base sobre a qual se funda a hospitalidade $\mathrm{e}$ as leis sob as quais ela é

\footnotetext{
${ }^{3}$ Esse termo refere-se a um conceito central para a psicologia moral e para a ética dos estóicos gregos, conforme explicitado adiante.

${ }^{4} \mathrm{O}$ radical hôte em francês designa tanto o hóspede como o hospedeiro.
} 
exercida.Entretanto, o respeito e a tolerância que constituem os princípios da hospitalidade podem dar lugar à exclusão e à fobia, na medida em que o hóspede é um estrangeiro, um estranho, hostis (no latim), que remete tanto ao que merece acolhimento quanto ao que merece hostilidade por comparecer com sua estrangeiridade. Essa conjunção de sentidos é marcada pelo termo derridianohostipitalidade, asseverando o caráter regrado, normativo e condicional da hospitalidade, tal qual é exercida na contemporaneidade.

$\mathrm{O}$ aspecto em que a estrangeiridade parece provocar maiores desestabilizações subjetivas é a tomada da palavra na língua do outro, tanto por parte do que migra como daquele que o acolhe.

A língua dita materna é normalmente representada como sendo o elo inquebrantável entre o migrante e o território designado natal. Derrida (em DUFOURMANTELE, 2003, p.79) a reputa como a "última pátria", a "última morada", a "primeira e última condição de pertencimento" dos estrangeiros. Toda e qualquer relação que o mundo deixa marcada em alguém e que alguém estabelece com o mundo a sua volta é intermediada pela língua dita materna. Assim, mesmo separado de seu território, o migrante carrega consigo algo que pode chamar de seu, não importa o que aconteça. A língua torna-se, então, a garantia de uma certa estabilidade, um território guardado para sempre como familiar, em que o sujeito pode desfrutar certa segurança devido à ilusória determinação do universo simbólico nomeado com as palavras de sua língua. Os equívocos constitutivos dos processos linguageiros e os consequentes embaraços são ignorados em favor desse sentimento de se sentir em casa na "sua" língua. Essa língua como um chez-soi (DERRIDA, em DUFOURMANTELLE, 2003, p.81) por vezes resta como traço da ilusão de origem e de pertencimento, traço que identifica aquele que por ela se deixa contar e se conta, traço que pode, também, representar o júbilo da identidade, ou seja, o ponto de convergência entre um lugar e aquele que se representa pela língua associada a esse lugar.

É preciso lembrar, porém, que essa língua que primeiro veicula a lembrança daquela que nos introduziu (n)a linguagem já é, desde sempre, língua do Outro. Assim, o encontro-confronto com a língua do outro instaura a dupla injunção que se impõe sobre o migrante: aventurar-se no universo simbólico pelas vias de uma língua estrangeira, implicando assentir em se ver tomado em uma outra posição discursiva no 
mundo, instauradora de novas discursividades; e confrontar o que já estava bem tecido com as palavras da língua dita materna, experimentando, assim, a instabilidade que resulta da constatação da diferença e um provisório exílio da assumida identidade nacional.

Semelhantemente, aquele que recebe o migrante no território "de acolhida" experimenta a desestabilização resultante do encontro-confronto com a diferença que estraçalha a ilusão de homogeneidade e unidade na língua. O sotaque que habita os modos como o migrante ensaia seu dizer na língua de acolhida pode, a princípio, soar como música ao ouvido do que acolhe. Os equívocos no processo de nomeação de mundo na língua designada inconstestavelmente como sendo materna daquele que recebe podem ser reputados como engraçados, a princípio. A não correspondência entre os comportamentos esperados do estrangeiro e aquilo que efetivamente ele consegue realizar pela palavra talvez institua uma certa inveja do modo diferente pelo qual o outro se relaciona com o mundo. Contudo, basta que o migrante insista em sua diferença para suscitar impaciência e resistência. Logo o prazer do ritmo e o engraçado na língua podem dar lugar à impaciência, seja pela dificuldade de vermos a língua que chamamos "nossa" e nos remete à maternidade que reputamos a ela "maculada" pelo estrangeiro; seja pela constatação de que o que estava aparentemente tão bem significado pelas palavras da língua materna possa receber outras significações e, necessariamente, seja passível do equívoco. Caso o estrangeiro insista em presentificar seu modo peculiar de ser e estar no mundo, rapidamente o exotismo que suscitava a inveja pode dar lugar à resistência e ao ódio à diferença.

Essas questões são direta ou indiretamente tratadas pelos artigos que compõem este volume.

No primeiro artigo, "O conceito "Língua de Herança" na perspetiva da Linguística e da Didática de Línguas: considerações pluridisciplinares em torno do perfil linguístico das crianças lusodescendentes na Alemanha", Melo-Pfeifer discorre sobre o conceito "língua de herança" e propõe uma articulação dos princípios linguísticos que embasam tal conceito com as contribuições da Didática de Línguas. A análise de entrevistas de alunos alemães aprendizes de português evidencia a possibilidade de confluência e de divergência entre ambas as perspetivas disciplinares, 
nas suas abordagens ao desenvolvimento de competências linguísticas em contexto migratório.

Com base na noção de resistência desenvolvida na perspectiva foucaultiana, Leite discute como a subjetividade de um imigrante é discursivisada em um blog, no artigo "Imigrante angolano e subjetividade em conflito: e(in)screver-se e resistir em blog”. O pressuposto é de que as narrativas ali presentes se relacionem a um exercício de escrita de si, uma via para a construção da subjetividade, e que indícios de resistência, materializados em elementos discursivos, apontariam para os conflitos na subjetividade.

Delong e Kersch, no artigo "Perfil de descendentes de poloneses residentes no sul do Brasil: a constituição da(s) identidade(s)", analisam como, na fala de um jovem padre descendente de poloneses, ele constitui a sua identidade étnica e social e como a religiosidade dessa etnia ajuda a manter a língua viva entre os falantes, inclusive os da área urbana.

A problematização do processo de constituição identitária dos indígenas a partir do discurso do "Documento Final do Acampamento Terra Livre 2011 - pelo direito à vida e à mãe Terra" é o ponto central do artigo Guerra e Valiente, intitulado "Entre o discurso do "Acampamento Terra Livre" e a (ex)(in)clusão social, o (per)curso identitário dos povos indígenas". Os autores analisam as representações sociais de exclusão que constituem o discurso do documento oficial sobre os indígenas, a partir da perspectiva discursiva e do processo de referenciação linguística, com base na interpretação de regularidades enunciativas que nos possibilitem rastrear, pela materialidade linguística, os efeitos de sentido possíveis, as formações discursivas e os interdiscursos que perpassam o discurso do movimento indígena "Acampamento Terra Livre" (ATL).

No artigo "Contradições e hierarquias nas ideologias linguísticas do Conselho Nacional de Imigração", Pinto propõe analisar o impacto das mudanças dos fluxos migratórios para o Brasil nas configurações das ideologias linguísticas circulantes nas decisões debatidas e registradas em atas do Conselho Nacional de Imigração (CNIg) e discutir as consequências dessas novas configurações para as hierarquias identitárias nacionais. 
Por sua vez, Benites, no artigo "Estrangeiridade e hospitalidade: representações sobre migrantes na mídia mato-grossense" aborda as representações que a mídia matogrossense faz de migrantes sulistas no Estado a partir de textos jornalísticos, a fim de interrogar a temática da (i)migração e os efeitos de sentidos que emergem na mídia escrita.

Por meio da análise do filme Espanglês (BROOKS, L. James. [Dir.] Spanglish. DVD, EUA: 2004), Souza focaliza o complexo processo de migração na contemporaneidade, as consequentes questões de linguagem, subjetividade e o processo de aquisição/aprendizagem de línguas envolvidos. Para tanto, seu artigø intitulado "Migração, linguagem, subjetividade e o complexo processo de aquisição/aprendizagem de línguas representados em Spanglês" tece suas considerações amparando-se nas principais teorias e modelos de aquisição/aprendizagem de línguas, que vão da perspectiva linguística à sociocultural.

$\mathrm{O}$ artigo que fecha este número, "Imigração chinesa em São Paulo e seu português falado", aborda aspectos gerais da imigração dos chineses no Brasil, especificamente, São Paulo. Yin Bi discute as situações de contato vividas pelos chineses com as línguas chinesas e o português falado para analisar os efeitos comunicativos e gramaticais resultantes dessas situações de contato interativo nas ruas de São Paulo.

Concluo enfatizando que os impasses subjetivos decorrentes da experiência de estrangeiridade abrem portas para modos de subjetivação que colocarão em cheque a relação que alguém entretém com o universo simbólico que o constitui, ensejando ora a afirmação da diferença, ora a negação da mesma. A crescente demanda por deslocamentos espacio temporais impõe que o sujeito empreenda constantes tentativas para fazer sentido de sua experiência no mundo. Uma das condições para se embarcar nessas empreitadas é fazer o luto da questão da origem, permitindo-se desvencilhar de algumas amarras identificatórias que conferem uma ilusória unidade e uma mítica posse de umterritório subjetivo e espacial e, consequentemente, podem representar a manutenção de uma posição reprodutora inerte e sem novidade alguma. A desistência de tal posição enseja a ousadia necessária para enfrentar o entranho e desbravar outras pairagens. Nesse sentido, somos todos, um pouco, migrantes, pois enveredamos, por vezes, no processo do luto de uma unidade imaginária para, em seguida, sermos capazes 
de engendrar para nós mesmos outras novas posições de ser e de estar no mundo. Sem temer o inusitado, Elzira Uyeno, inspiradora desta coletânea, foi uma migrante irrevogável, provando-nos, com sua existência, que viver é assumir riscos, responsabilizar-se pelos sentidos que damos a eles, para que, ao findar nossa trajetória, deixemos nossos rastros no mundo como legado.

Carla Nunes Vieira Tavares Organizadora desta edição

\section{Referências}

DUFOURMANTELE, A. Anne Dufourmantelle convida Jacques Derrida a falar da Hospitalidade. São Paulo: Escuta, 2003.

GIDDENS, A. As consequências da modernidade. São Paulo: UNESP, 1991.

IANNI, O. A sociedade global. Rio de Janeiro: Civilização Brasileira, 1996.

KOLTAI, C. Migração e racismo: um sintoma social. In: PÓVOA NETO, H.; FERREIRA, A. P. (orgs). Cruzando fronteiras disciplinares: um panorama dos estudos migratórios. Rio de Janeiro: EAPERJ; Revan, 2005. pp.173-181.

KRISTEVA, J. Estrangeiros para nós mesmos. Rio de Janeiro: Rocco, 1994.

LACAN, J. O Seminário livro 17: o avesso da psicanálise. Rio de Janeiro: Zahar, 1992.

OLIVEIRA, P. R. M. O migrante, seu drama psíquico e a percepção das diferenças. In: PÓVOA NETO, H.; FERREIRA, A.P. (orgs). Cruzando fronteiras disciplinares: um panorama dos estudos migratórios. Rio de Janeiro: FAPERJ; Revan, 2005. pp. 163-173. 